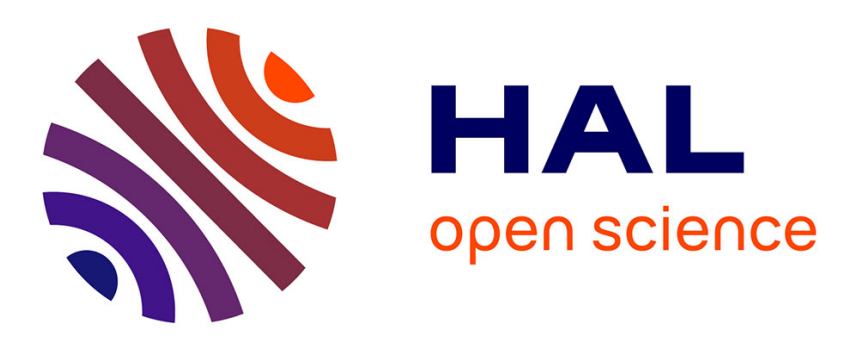

\title{
DOMAIN WALL PINNING IN INHOMOGENEOUSLY DEFORMED AMORPHOUS ALLOYS
}

\author{
M. Gibbs, J. Evetts, M. Horton
}

\section{To cite this version:}

M. Gibbs, J. Evetts, M. Horton. DOMAIN WALL PINNING IN INHOMOGENEOUSLY DEFORMED AMORPHOUS ALLOYS. Journal de Physique Colloques, 1980, 41 (C8), pp.C8-706-C8709. 10.1051/jphyscol:19808178 . jpa-00220280

\section{HAL Id: jpa-00220280 https://hal.science/jpa-00220280}

Submitted on 1 Jan 1980

HAL is a multi-disciplinary open access archive for the deposit and dissemination of scientific research documents, whether they are published or not. The documents may come from teaching and research institutions in France or abroad, or from public or private research centers.
L'archive ouverte pluridisciplinaire HAL, est destinée au dépôt et à la diffusion de documents scientifiques de niveau recherche, publiés ou non, émanant des établissements d'enseignement et de recherche français ou étrangers, des laboratoires publics ou privés. 


\title{
DOMAIN WALL PINNING IN INHOMOGENEOUSLY DEFORMED AMORPHOUS ALLOYS
}

\author{
M.R.J. Gibbs, J.E. Evetts and M.E. Horton ${ }^{\star}$ \\ Department of Metallurgy and Materials Science, University of Cambridge, Combridge, England. \\ "Cavendish Laboratory, Madingley Road, Cambridge, England.
}

\begin{abstract}
Inhomogeneous deformation in amorphous alloys is characterized by local regions of intense shear. Experiments on VITROVAC $0040\left(\mathrm{Fe}_{40} \mathrm{Ni}_{40} \mathrm{~B}_{20}\right)$ supplied by Vacuumschmelze (Hanau, Germany) show a direct correlation between the number density of the shear bands and the coercive field after inhomogeneous deformation by cold rolling. The deformation process is also shown to induce an off axis magnetic anisotropy whose mean value is large compared to other residual and induced anisotropies in these materials. On this basis a domain structure is proposed for deformed material, and a model for coercivity based on domain wall pinning at residual stresses remaining after deformation is shown to lead to reasonable estimates of the coercive force.
\end{abstract}

\section{INTRODUCTION}

Metallic amorphous alloys display a characteristic inhomogeneous deformation mode when deformed under high stresses at temperatures below the glass transition temperature. Theoretical models ${ }^{1,2}$ for the deformation process are based on ideas of stress driven creation of free volume leading to a dilation of the matrix. The dilation regions extend and interconnect until they span the ribbon and allow macroscopic shear to occur on a plane. External evidence for macroscopic shear is seen in the shear steps that are found on the surface of inhomogeneously deformed material. Luborsky et a ${ }^{3}$ have shown that material deformed by cold rolling has a large coercive field, $\mathrm{H}_{\mathrm{C}}$, that increases with the level of deformation. In an extension of this work Gibbs et $a 1^{4}$ demonstrated that the domain wall pinning interaction leading to changes in $\mathrm{H}_{\mathrm{C}}$ lies in the bulk of the ribbon, and is associated predominantly with local fluctuations in strain. We present here measurements that give information on the nature of these pinning centxes and on the general way in which they interact with the domain structure to determine the magnetization process.

\section{EXPERIMENTAL \& RESULTS}

The experiments wexe carried out on VITROVAC $0040\left(\mathrm{Fe}_{40} \mathrm{Ni}_{40} \mathrm{~B}_{20}\right)$ supplied by Vacuumschmelze, Hanau, Germary. The shear band distribution after varying amounts of deformation was studied using the following technique. A narrow rectangular depression was formed on the ribbon surface by masking with resist and electropolishing in a 10\% perchloric in glacial acetic acid solution at $-30^{\circ} \mathrm{C}$.
About $6 \mu \mathrm{m}$ of material wąs removed sufficient to ensure that the region was not marked during rolling. The depression did not affect the rolling process as its width was much smaller than the ribbon width. The level of deformation was controlled by varying the number of passes through the rolling mil1 ${ }^{5}$ at a fixed closure pressure. The thickness of rolled ribbon was uniform to within $1 \mu \mathrm{m}$. The variation in the shear band configuration was determined by optical microscopy viewing under green light. The shear bands were at $90^{\circ}$ to the rolling direction, their mean spacing was found from an average of 200 bands for each specimen. A few specimens were also viewed in SEM to check that bands with small shear steps were not being missed, a small degree of bifurcation of shear bands was observed that was not obvious in the optical micrographs.

After rolling, the DC magnetic hysteresis loop was measured in fields up to $2.10^{4} \mathrm{Am}^{-1}$ using a standard technique ${ }^{4}$. Values of $H_{c}$ and $\bar{k}$, the mean off-axis magnetic anisotropy, were obtained from these curves; the latter from the area under an interpolated reversible curve. The rolled ribbons were also measured with a tensile load applied at the ends to investigate the effect of additional applied tensile strain on $\mathrm{H}_{\mathrm{C}}$ and $\overline{\mathrm{K}}$.

The variation of ribbon thickness and coercive field with the number of passes through the rolling mill are shown in Fig.1. The coercive field is very sensitive to the level of deformation rising by two orders of magnitude for five passes, (as 
received value $4 \mathrm{Am}^{-1}$ ).

(a)

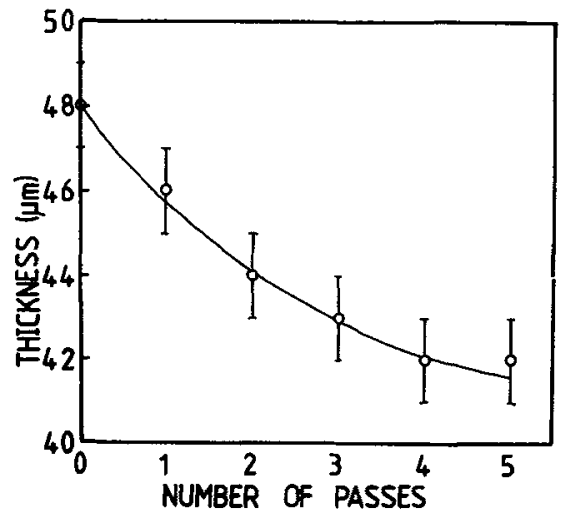

(b)

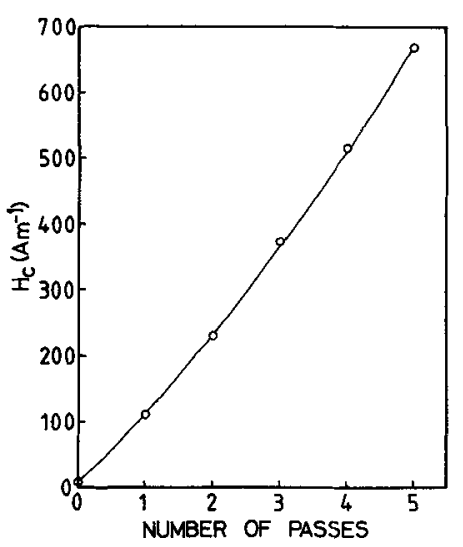

Fig.1. (a) The variation of ribbon thickness with the number of passes through the rolling mill (b) the variation of coercive field, $\mathrm{H}$, with the number of passes through the rolling mill.

The variation of the mean shear band spacing with the number of passes is shown in Fig. 2, two sets of data are presented, one for a single sample rolled and viewed after each pass and one for a set of samples rolled with different numbers of passes. Chen ${ }^{6}$ quotes an isolated value of $1.25 \mu \mathrm{m}$ for the shear band spacing in a Pd-CU-Si amorphous alloy rolled to a thickness reduction of $30 \%$. This is in reasonable agreement with the data presented here.

The correlation between coercive field and shear band spacing is shown in Fig. 3. The coercive field rises sharply with decreasing shear band spacing, increasing by a factor of six when the mean spacing is reduced from $3.5 \mu \mathrm{m}$ to $1.7 \mu \mathrm{m}$. As $H_{C}$ increases the remanence decreases, dropping by a factor of three over the same interval. The low remanance to saturation ratio and the general shape of the hysteresis loop with a slow approach to saturation is consistent with a mean induced magnetic anisotropy, $\bar{k}$, with an easy axis directed out of the ribbon plane. For a sample with five passes $\bar{k}$ was estimated, from a measurement of the area under the magnetization loop, to be about $8.10^{3} \mathrm{Jm}^{-3}$. For the same sample with an applied tensile load both $\overline{\mathrm{K}}$ and $\mathrm{H}_{\mathrm{C}}$ were reduced, the former more rapidly than the latter. For an applied tensile stress of $0.5 \mathrm{GPa}$, (25\% yield), $\overline{\mathrm{K}}$ fell to $2.10^{3} \mathrm{Jm}^{-3}$ while $\mathrm{H}_{\mathrm{C}}$ fell from $670 \mathrm{Am}^{-1}$ to $300 \mathrm{Am}^{-1}$. The changes were reversible on removal of the applied load.

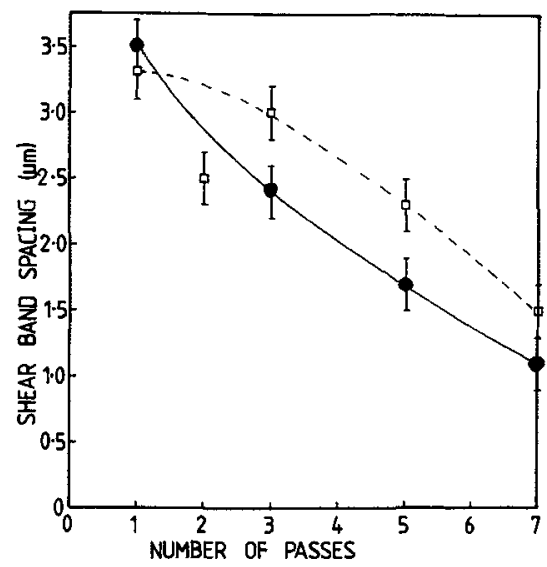

Fig. 2. The variation of mean shear band spacing with the number of passes through the rolling mill. (- single sample : 口 separate samples)

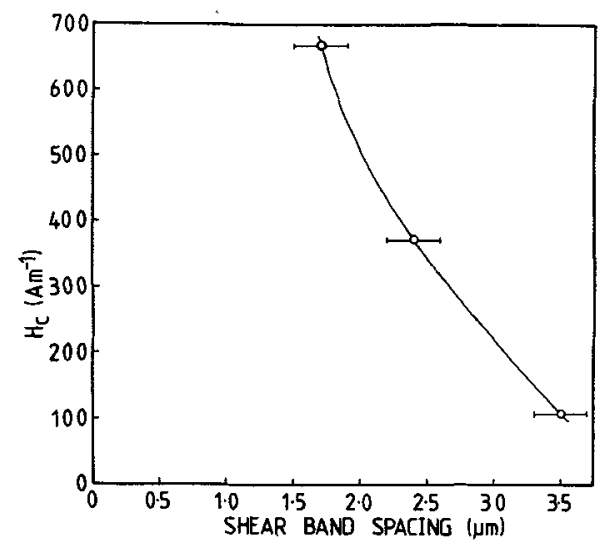

Fig. 3. The variation of coercive field, $H_{C}$, with mean shear band spacing.

DISCUSSION

Our observations indicate that the basic domain structure is strongly modified by roll induced anisotropy. In addition there is increased hysteresis through domain wall pinning at a residual defect structure. The effects are complex and deformation must be viewed as affecting the whole magnetization process. The observed changes are predominantly stress related ${ }^{4}$, hence a stuđy of magnetic effects in these materials leads to a deeper understanding of the inhomogeneous deformation process, in particular the nature and distribution of residual stresses in rolled material. 
Spaepen ${ }^{1}$ and Argon $^{2}$ have developed a model for inhomogeneous deformation in amorphous alloys based on the presence of free volume as an intrinsic component of an amorphous matrix of atoms. This free volume will be distributed statistically throughout the matrix. In the densest packed regions a large activation energy is required for atomic rearrangement, in other regions the activation energy is low er. On the application of a stress they argue that there can be a stress-driven creation of further free volume, this occurring first in the regions needing the lowest activation energy. As the dilation continues individual regions which are shearing according to this mechanism will merge and eventually a contiguous path may be formed to the sample surfaces allowing macroscopic flow to occur on shear bands at $45^{\circ}$ to the ribbon surface.

Based on this model it is possible to make certain deductions about the nature and distribution of local fluctuations in stress and strain. The in duced magnetic anisotropy is most directly related to the distribution of strain. The random structure of a fully relaxed material will have a local random anisotropy arising from short range strain fluctuations $^{7}, \overline{\mathrm{K}}$ will however average to zero as the inverse square root of the volume. In contrast, the strain fields of defect sites formed during inhomogeneous deformation will average to give a finite $\bar{k}$. This is because the macroscopic applied stress will produce uniformly orientated defects whose strain fields add coherently to give a mean 'deformation induced anisotropy'.

Two types of strain centre are proposed. Firstly there will be the regions of the matrix that have undergone stress induced dilation and plastic deformation but which have not formed contiguous paths to the ribbon surface. Argon ${ }^{2}$ argues that the favoured transformation configuration is a disc shaped region containing the shear transformation direction in its plane. With this site the dilated region and the matrix will be in compression, the strain field in the matrix is a combination of $i$ ) a compression similar to the stress field of a prismatic interstitial dislocation loop in a crystal and ii) a shear component similar to the stress field of a dislocation loop with an in plane Burgers vector. The magnetic easy axis will vary spatially, its averaged direction being out of the ribbon plane. The second mechanism for stress storage in the sample comes from the fact that shear ceases on macroscopic shear bands on removal of the load. The free volume model for this flow suggests that material in the band is behaving as a viscous liquid, thus it is possible to draw an analogy between the quenching of the material during production and the cessation of shear on these bands. As soon as shear ceases relaxation will commence placing the matrix interface under biaxial compression. Contributions from different shear bands will add coherently to give a mean anisotropy axis pexpendiculax to the shear bands. Also it is likely that the cessation of shear and subsequent relaxation will proceed nonuniformly across a shear band. This will lead to large local stress fluctuations across each shear band similar to the 'quenched-in' tensile and compressive regions in as-cast material. Locally it is possible that the stress will rise above the measured yield strength, ( $2 \mathrm{GPa}$ for $\mathrm{Fe}_{40} \mathrm{Ni}_{40}{ }^{\mathrm{B}}{ }_{20}^{8}$ ), and in dense packed regions may approach the theoretical strength. Local peaks in strain produce large fluctuations in magnetic anisotropy and act as domain wall pinning sites.

Experimental evidence for this model can be drawn from several souxces. On re-rolling a ribbon the dilated regions left in the matrix will act as sites for the formation of further shear bands; shear will also be likely to continue on bands already nucleated. Krishnanand and $\mathrm{Cahn}^{9}$ have shown that the tendency for shear to continue on the same bands on a repeated bend test can be removed by annealing the material. This supports the idea of defect-like structures being stored in the material on the removal of the load.

The coherent addition of stress and strain fields of the residual defect sites is confirmed by the observation of a sizeable off axis $\overline{\mathrm{K}}=8.10^{3} \mathrm{Jm}^{-3}$ for five passes. This value for $\overline{\mathrm{K}}$ receives independent support from the stress broadening of the Curie temperature $T_{C}$ as observed by differential scanning calorimetry. Taking ${ }^{2 T} c / \partial p=-7 \mathrm{~K} \mathrm{GPa}^{-1} 10$ and a typical spread of $\pm 2 \mathrm{~K}$ about the curie point for undeformed ribbon we obtain a value for the average stress, $\bar{\sigma}=0.3 \mathrm{GPa}$, whence $\overline{\mathrm{K}}=\frac{3}{2} \lambda \bar{\sigma}=$ $4.5 \times 10^{3} \mathrm{Jm}^{-3}$ (the magnetostriction $\lambda=10^{-58}$ ). Also the application of a tensile load of $0.5 \mathrm{GPa}$ was observed to turn the easy axis closer to the ribbon axis (off axis $\overrightarrow{\mathrm{K}}$ reduced fourfold).

The magnitude and direction of $\overrightarrow{\mathrm{K}}$ will determine the magnetic domain structure in the material. since the easy axis points out of the ribbon plane 
the bulk of the sample will be magnetized parallel and anti-parallel to this direction with $180^{\circ}$ walls perpendicular to the ribbon axis, the domain width is 1 ikely to be about $2 \mu \mathrm{m}$ (depending only weakly on $\overline{\mathrm{K}}^{11}$ ). The mean domain wall width is $d_{\mathrm{w}} \sim 0.2 \mu \mathrm{m}$ for five passes (varying as $\overline{\mathrm{K}}^{\frac{1}{2}}$ ). The surfaces of the ribbon will be covered in a simple closure domain structure to avoid magnetic free poles. Within the closure domains the magnetic moment will be in hard directions, parallel and anti-parallel to the ribbon axis 11,12 .

For non-zero applied magnetizing fields the closure pattern will be altered by the growth of the domains aligned parallel to the applied field. Rotation of the bulk domains will not occur for applied fields $\sim \mathrm{H}_{\mathrm{C}}$ since $\mathrm{H}_{\mathrm{C}} \ll \mathrm{H}_{\mathrm{K}}$ the anisotropy field, $H_{K}=2 \bar{K} / M_{S}\left(M_{S}=1 \mathrm{~T}\right.$ for $\left.\mathrm{Fe}_{40}{ }^{N i_{40}{ }_{20}}\right)$. Thus the main features of the magnetization process at low fields depend on the motion of $90^{\circ}$ closure domain walls and their interaction with pinning sites at the local stress fluctuations discussed above. Support for wall pinning at sites with higher than average strain is seen in the relatively slow fall in $\mathrm{H}_{\mathrm{C}}$ with applied tensile load $(45 \%$ for $0.5 \mathrm{GPa}$ load).

In calculations of $\mathrm{H}_{c}$ factors such as wall bowing and whether the pinning must be summed statistically or can be estimated from a simple potential theory are important. If material parameters vary on a scale less than the domain wall width a micromagnetic treatment is required.

For the system in question the rapidly rising $\mathrm{H}_{\mathrm{C}}$ coupled with a falling remanance indicates that for wide shear band separation, $L$, only a fraction of the closure domain structure is subject to strong pinning forces. The major source of pinning is therefore likely to be the shear band defect structure. For large $\mathrm{L}$ the measured $\mathrm{H}_{\mathrm{C}}$ is not simply related to the pinning force. However for $\mathrm{L}<1.5 \mu \mathrm{m}$ each closure domain is intersected by at least one shear band (on average $1 / \sqrt{2} \mathrm{~L}$ shear bands per unit length). We restrict attention to this regime. Since $d_{w} \simeq 0.2 \mu \mathrm{m}$ and $\mathrm{H}_{\mathrm{C}}>700 \mathrm{Am}^{-1}$, we must assume that the important strain defect sites have dimension $d>d_{w}$ in order to get sufficient pinning on any reasonable model. If the spacing between defect sites in a shear band is nd where $n>3$ we may assume the wall is flexible and estimate $\mathrm{H}_{\mathrm{C}}$ using the potential theory approach putting $2 M_{S} H_{C} \sim\left({ }^{\partial E} E_{w / X}\right)_{\max }$ where $E_{w} \sim 4(A K)^{\frac{1}{2}}$ is the do- main wall energy per unit area. The exchange constant $\mathrm{A}=3 \cdot 10^{-12} \mathrm{Jm}^{-1} 11$ relates to $\mathrm{T}_{\mathrm{C}}$ and will not make a significant contribution to the energy variation. To reach a position of maximum force a closure domain must move a distance $\mathrm{d} / 4$, thus

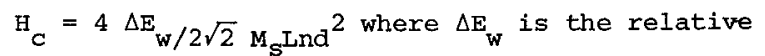
change in $\mathrm{E}_{\mathrm{w}}$. For a single defect site assumed to have an effective stress of $2 \mathrm{GPa}$ (the yield strength), $K=3.10^{4} \mathrm{Jm}^{-3}$. Whence $\Delta E_{W}=4 A^{\frac{1}{2}}\left(K^{\frac{1}{2}}-\bar{K}^{\frac{1}{2}}\right) \pi d^{2}$ so that the coercive field is, $\mathrm{H}_{\mathrm{C}} \simeq 16(\mathrm{AK})^{\frac{1}{2}} / \mathrm{M}_{\mathrm{S}} \mathrm{Ln}$ for $\mathrm{L}=1.5 \mu \mathrm{m}, \mathrm{H}_{\mathrm{C}}=3200 / \mathrm{n}^{\prime}$ the measured value of $\mathrm{H}_{\mathrm{C}}$ is $2800 \mathrm{Am}^{-1}$ which indicates a value of $\mathrm{n}=4$, a reasonable value since it indicates that only $1.5 \%$ of the material has this very high level of strain.

In conclusion, it has been possible to explain qualitatively the observed magnetic anisotropy, and coercive field dependence on deformation by building up a model of the array of defect sites and their associated strain fields based on the current understanding of the inhomogeneous mode of deformation. The model is seen to give an explanation of various mechanical properties as well as the the magnetic properties quoted here.

\section{ACKNOWLEDGEMENTS}

Discussion with Drs. W.M. Stobbs, D.R.H. Jones and C.R. Calladine is gratefully acknowledged. Thanks are due to Prof. R.W.K. Honeycombe for interest in the project, and M.R.J.G. acknowledges financial support from the S.R.C. and C.E.R.L. REFERENCES

1) F.Spaepen, Acta Met. 25 (1977) 407

2) A.S.Argon, Acta Met. $\overline{27}$ (1979) 47.

3) F.E. Luborsky, J.L.Walter and D.G. LeGrand, IEEE Trans. Mag. MAG-12, (1976) 930.

4) M.R.J.Gibbs, J.E.Evetts and N.J.Shah, J. Appl. Phys. 50 (1979) 7642.

5) M.R.J.Gibbs and J.E.Evetts, Scripta Met.14 (1980) 63.

6) H.S.Chen, Appl.Phys. Letts.29 (1976) 328.

7) J.E.Evetts, W.Howarth and M.R.J.Gibbs, Proc.3rd. Int.Conf.Rapidly Quenched Metals, (Metals Society, London, 1978), p.127.

8) Vacuumschmelze preliminary data sheet.

9) K.D.Krishnanand and R.W.Cahn, Scripta Met. 9 (1975) 1259.

10) T.Mizoguchi, A.I.P. Conf. Proc.34(1976) 286.

11) G.Schroeder, R.Sctrafer and H.Kronmilier, Phys. Stat. Sol. (a) 50 (1978) 475.

12) H-R Hilzinger, Phys. Stat. Sol. a) 38 (1976) 487 and $\mathrm{H}-\mathrm{R}$ Hilzinger and $\mathrm{H}$. Kronmüliler J. Mag. Mat. $\underline{2}$ (1976) 11 . 